\title{
Research of high-speed HFC-boriding kinetics
}

\author{
Vladimir Malikov ${ }^{1, *}$, Alexander Shegolev ${ }^{2}$ and Alexey Ishkov ${ }^{2}$ \\ ${ }^{1}$ Altay State University, Lenina, 61, Barnaul, Russia \\ ${ }^{2}$ Altay State Agricultural University, Krasnoarmeysky, 73, Barnaul, Russia
}

\begin{abstract}
The paper presents studies boride coatings, which were created using high-frequency treatment with currents. Chemical reactions characterized the boriding procedure at various temperatures are show. The choice of the main element, of the reaction-boriding scheme is characterize, their role is revealed, and the probable processes leading to the realization of topochemical boriding initiated by HFC-heating are established. The kinetic curves received during the test at different temperatures are showed. Anamorphoses of the kinetic curves are showed, and the values of activation energy and parameters of the boriding process using HFC-heating are calculated on the basis of linearization of the Arrhenius equation.
\end{abstract}

\section{Introduction}

Obligeding to the great properties (high yield strength, great strength to weight multiplier and good corrosion resistance) [1, 2], steel fusions are widely gone in aerospace and chemical industries. Nevertheless, low hardness and poor wear-friction restrict their use, especially in tribological applications [3, 4]. Most studies are an try to enhance their deterioration resistance using many surface hardening techniques [5]. Boriding, as one of the effective surface hardening treatments, can cause boron (B) atoms to diffuse through the metal substrate and effectively produce one or more hard boride layers, providing a significant enhancement in surface hardness and tribological properties [6, 7]. Boriding, owing to its simplicity, low cost, and flexibility properties, compared with another processes hardening, has been the most frequently used in hardening of steel. It can make hard (TiB2 and TiB) boride layers on the superficies of steel alloys [8, 9], following in the enhancement of the properties (such as microhardness, compressive strength, and yield stress) and corrosion resistance for steel alloys $[10,11]$.

However, due to its relatively high treatment temperature and long treatment time, some defects (such as the microstructural changes and large deformation of base materials) are likely to be caused [12], largely affecting the mechanical properties and precision of borided samples. In order to deal with such prominent defects, during solid state boriding of steel alloy, rare earth (RE) elements can be used $[13,14]$. It can not only accelerate the growth kinetics of boride layer [15] but also promote the efficiency of boriding process and save the treatment time. Thus, compared with the conventional solid state boriding of steel alloy, RE additions-solid state boriding (REs-boriding) can largely reduce the impact of high

\footnotetext{
* Corresponding author: osys11@gmail.com
} 
temperature and long treatment time on the mechanical properties and precision of base alloy, which can help to ensure the mechanical properties of base alloy as much as possible.

From the viewpoint of kinetics, the modeling for boriding kinetics can be regarded as a way to estimate the boride layer thicknesses to meet the various employment requirements of borided materials [16-17]. Furthermore, there are a few studies exploring the modeling of the accelerated kinetics of boride layer growth for the solid state boriding of steel alloy. Recently, B.Sarma and K.S.Ravi Chandran established a diffusion model to estimate the effect of the boriding temperatures that are very close to the $\beta$-transus temperature on accelerating the kinetics of boriding of CP-Ti [18]. However, until now, no study is found to develop a kinetic model to quantitatively estimate the effect of RE on accelerating the kinetics of solid-state boriding.

In is necessary to carry out researches of SHS processes in a base model system and its modified versions in order to establish the rules governing the initiation and combustion of a charge of various compositions, as well as to control this process followed by a possibility of obtaining high-quality hardening boride coatings on the surface of a steel part with a thickness of at least 150-200 $\mu \mathrm{m}$, and development of an active prototype technology.

The chosen area is relevant, since only a few works among the known ones are devoted to the use of HFC-heating in boriding, and the combination of various factors, stages and types of boriding in one process is one of the most widely studied areas in boriding (at least the diffusion one), and the use of a surface chemical (topochemical) reaction between iron and boron in order to obtain coatings, possible in the systems under study, is a new direction in boriding.

According to the data presented in paper [19], the first exothermic effects become apparent in oxides, mixtures of iron (II, III) oxide and iron spinel $\mathrm{FeO}$ and $\mathrm{Fe}_{2} \mathrm{O}_{3}$ with amorphous and crystalline boron under conditions of heating even at a temperature of 350 ${ }^{\circ} \mathrm{C}$, which is explained by the reduction reaction of iron oxides with boron according to the following equations:

At higher temperature $\left(500,700{ }^{\circ} \mathrm{C}\right)$, additional exo-effects are observed caused by targeted reactions of the formation of $\mathrm{FeB}$ and $\mathrm{Fe} 2 \mathrm{~B}$ borides and oxygen compounds of elements according to the following equations:

$$
6 \mathrm{FeO}+5 \mathrm{~B}=3 \mathrm{FeB}+\mathrm{Fe}_{3}\left(\mathrm{BO}_{3}\right)_{2},
$$

Then, extending the provisions of paper [20], the total process of boriding of the oxidized steel surface can be described by the following reaction:

$$
2 \mathrm{Fe}_{2} \mathrm{O}_{3}+8 \mathrm{~B}=4 \mathrm{FeB}+2 \mathrm{~B}_{2} \mathrm{O}_{3},
$$

When the process proceeds not in a powder mixture, but on the surface of a compact material, as in case of boriding using HFC-heating, the FeB boride formed on the steel surface will further react with the base metal, propagating into its depth and forming $\mathrm{Fe}_{2} \mathrm{~B}$ boride according to the reaction:

$$
\mathrm{FeB}+\mathrm{Fe}=\mathrm{Fe}_{2} \mathrm{~B},
$$

and the final composition of the boride coating will also depend on Fe2B disproportionation at higher temperatures.

Thus, the equilibrium state of the reversible reaction will definitely also have influence upon the chemical and phase composition and the structure of layers formed on the surface of steels during a topochemical reaction with boron at high temperatures ( $900{ }^{\circ} \mathrm{C}$ and more).

Additional acceleration of the topochemical process on a steel surface can also be achieved by using various deoxidizers present or specially introduced into the composition of fluxes used in HFC-surfacing and HFC-heating, thus simultaneously protecting the metal surface from oxidation and removing the process slags. 
Taking into opinion the fact that HFC-heating allows to heat the steel surface to temperatures of $900-1000{ }^{\circ} \mathrm{C}$, and all of the above reactions are exothermic, when applying HFC-heating for boriding, there is a real possibility not only to obtain boride coatings, but also to achieve their phase and structural homogenization due to remelting under the action of heat released in the surface layers during HFC-heating.

In paper [19], the thermodynamic calculations were also carried out and the Gibbs energy dependences were obtained for all observed and theoretically possible reactions, including those in the Fe-B system, and it was also shown that it has negative values (from -390 to $560 \mathrm{~kJ} / \mathrm{mole}$ ) across the entire studied temperature range and up to $1500{ }^{\circ} \mathrm{C}$, which means that these boriding reactions are possible, and the type of the obtained products will depend mainly on the kinetic and equilibrium parameters of the boriding process.

The above summary theoretical equation for the topochemical boriding of an oxidized surface also indicates the need for a multiple (up to 100-fold) theoretical excess of amorphous boron in the mixture relative to oxidized forms of iron (as amorphous boron has a very low density), which, furthermore, will change permanently in the process of boriding, as some part of the element will be spent for surface deoxidation, and the other part will take part in the target reaction.

Gases evolving in the melt during combustion can lead to scattering (dispersion) of the melt, increase in porosity, expansion, decrease in density of SHS-products, and impairment of process initiation. However, in preliminary experiments and during combustion of cylindrical molded specimens, a slight increase in volume of SHS-process products was noted as compared with the initial substances.

Based on these considerations, boron should be replaced by its compounds capable to decompose and release an active element $\left(\mathrm{B}_{4} \mathrm{C}\right.$, dissociating borides of s-metals and $\mathrm{p}$ elements of the periodic system, ferroboron, etc.) under high temperatures and/or chemical influences.

The above circumstances determined the substance of the researches reflected in this paper, and their results are sequentially presented below. Initially, we chosened the basic components of the reaction, established their role, and identified possible processes resulting in the topochemical boriding initiated by HFC-heating.

\section{Experimental technique}

To establish practically realizable reactions of surface chemical (topochemical) boriding and the accompanying high-temperature processes, a model mixture was prepared containing P0.66 flux and boron carbide at the following ratio, wt. \%: $\mathrm{B}_{4} \mathrm{C}-84, \mathrm{P}-0.66-16$ [21, 22].

The main component of the P-0.66 flux is an eutectic mixture of $\mathrm{B}_{2} \mathrm{O}_{3}$ and $\mathrm{Na}_{4} \mathrm{~B}_{2} \mathrm{O}_{7}$ with a mass ratio of substances of 0.66 , which melts when heated above $500-520^{\circ} \mathrm{C}$, forms complex mixtures of meta- and orthoborates, active boron in cationic (+) and anionic (-) forms, reacts with oxides on steel surface and other components of the mixture.

Calcium silicide $\left(\mathrm{CaSi}_{2}\right)$, included into the flux in an amount of up to $10-15 \% w t$, appears to be strong reducing agent, reactive compound, steel surface deoxidizing agent, and also as a high-temperature fluxer (due to released silicon) and others when starts thermally dissociate at $720-740{ }^{\circ} \mathrm{C}$ :

$$
\begin{aligned}
& 3 \mathrm{Ca}+\mathrm{B}_{2} \mathrm{O}_{3}=3 \mathrm{CaO}+2 \mathrm{~B}, \\
& 3 \mathrm{Ca}+\mathrm{Si}+\mathrm{B}_{4} \mathrm{C}=\mathrm{Ca}_{3} \mathrm{~B}_{2}+\mathrm{SiC}+2 \mathrm{~B}, \\
& \mathrm{Ca}+2 \mathrm{~B}_{4} \mathrm{C}=\mathrm{CaC}_{2}+8 \mathrm{~B},
\end{aligned}
$$


To elucidate the nature and the most probable mechanism of boriding using HFC-heating, the process kinetics was studied, when it was conducted based on a mixture applied to 65G steel samples. The process kinetics was studied both when carrying out the borating process using HFC-heating in a protective medium (Ar gas supplied at a rate of 1.5-2 L/min into an aluminum cartridge with an inductor and a sample placed in it), and when carrying out the process in air under normal conditions.

Since reactions 1, 2 are heterogeneous and occur at the interface of several solid phases, namely a solid starting material (steel surface, boriding agent, flux, etc.) - a solid reaction product $\left(\mathrm{FeB}, \mathrm{Fe}_{2} \mathrm{~B}\right.$ ), they can be considered as topochemical reactions (TCR).

Usually a topochemical reaction begins with the formation of seeds (nuclei) of crystallization of the solid reaction product on the surface of the initial solid. The centers of these nuclei are often associated with the presence of various types of defects on the surface: points of emergence of crystal lattice dislocations, vacancies (holes) or ions in interstices, crystal-crystallite interfaces in a polycrystalline material, domains, zones of nonstoichiometric composition, etc. Around these centers, nuclei, usually of a spherical type, start to grow. As they grow, the interface between the initial substance and the reaction product phases increases, and the reaction accelerates. When the nuclei fuse together and form a continuous reaction front, the phase interface and, accordingly, the reaction rate become maximum. Then, the process slows down due to the overlap of the nuclei themselves, which gradually disappear. From the presented phenomenological TCR model it can be seen that the rate of the entire process is determined by the rate of nuclei formation on the one hand, and by the rate of their growth and recombination on the other hand.

Like the rate of any chemical process, TCR depends on temperature and (to a lesser extent) pressure. Pressure dependence appears when gaseous components are the products or part of the starting materials of the TCR. At constant $p$ and T, the TCR rate is a certain function of $\alpha$, which must be determined from the experimental data.

Numerous experiments show [20] that the $\alpha=f(\tau)$ curve has a sigmoid form, and the $w$ $=f(\tau)$ curve has its maximum at a certain value of $\tau_{\max }$.

This type of kinetic TCR curves in general form is explained as follows. At the initial time, the rate of appearance of nuclei and their growth is low (TCR induction period), afterwards their surface begins to grow rapidly, so that the rate of the process becomes maximum by $w_{\max }$ the time $\tau_{\max }$, and the degree of transformation $\alpha$ reaches $\sim 0.5$ for most known TCRs, that is, a half of the starting substances are consumed by this time as a rule. After that, no new nuclei are formed due to the absence of a free surface, and the overlap of the existing ones results in a decrease in the area of phase interface, and thus the reaction begins to slow down. The phase interface moves into the volume of the solid phase, and the TCR rate slows down even more.

Therefore, the actual TCR mechanism will be determined by the processes of nucleation and their recombination, which is probabilistic, and for kinetic calculations of such processes, two approaches to the rate of nucleus formation are applied.

According to the first of them, the nuclei are formed according to the exponential law:

$$
N_{t}=N_{0}[1-\exp (-k t)] \text {, }
$$

where NO and Nt are the numbers of nuclei at the initial and an arbitrary points of time. The second approach is based on the power law of nucleation:

$$
N_{t}=K_{n} t^{n}
$$

Where $K_{n}$ is the nuclei growth factor, and $\mathrm{n}$ is a whole or fractional number $>1$.

In practice, the first mechanism is implemented very rarely, and the determining it TCR kinetic equations have a complex dependence $a=f(t)$. Therefore, to obtain the kinetic 
dependences of TCRs proceeding according to the second mechanism, the ErofeevKolmogorov equation is used:

$$
\alpha=1-\exp \left(-k t^{n}\right),
$$

where $n=\sigma+3$, or $n=\sigma+m$ in general case.

$\sigma$ is the number of units steps of transformation of a new phase crystallization center into a growing nucleus,

$m$ is the number of directions in which the nuclei grow, $m=1,2,3$, and other.

Then, the TCR rate constant and the value of $n$ can be easily found after double logarithmic transformation of dependence (12):

$$
\ln [-\ln (1-\alpha)]=\ln k+n \cdot \ln t,
$$

which, when displaying experimental values in $\ln [-\ln (1-\alpha)]=f(\ln t)$ coordinates, is a linear dependence, the parameters of which can be found graphically or by LSM.

The criterion for classifying the observed process as TCR will be a strong linear correlation of the experimental points of the linear dependence.

\section{Research results and their discussion}

In order to study the kinetics of boriding using HFC-heating, 65G steel specimens were boronized in a mixture for different periods of time. In our case the degree of transformation can be calculated by the formula:

$$
\alpha=\frac{h_{\max }-h_{t}}{h_{\max }},
$$

where $h_{\max }$ and $h_{t}$ are the maximum and the current boride coat thickness, respectively.

The kinetic curves obtained in the experiment at temperatures of 900,1000 and $1150{ }^{\circ} \mathrm{C}$ are shown in Figure 1.

As can be seen from Figure 1, the dependence of the thicknesses of boride coatings on steel 65G obtained at different temperatures of the process on the time of HFC-heating is sigmoid and has an induction period of $\sim 30 \mathrm{~s}$. The absence of noticeable processes in the system under study is obviously explained not so much by the accumulation of the number of nuclei in TCR, as by the release of a certain amount of active boron interacting with the steel surface according to reactions 4,5 , and 6 , which depend little on temperature within the range we have studied.

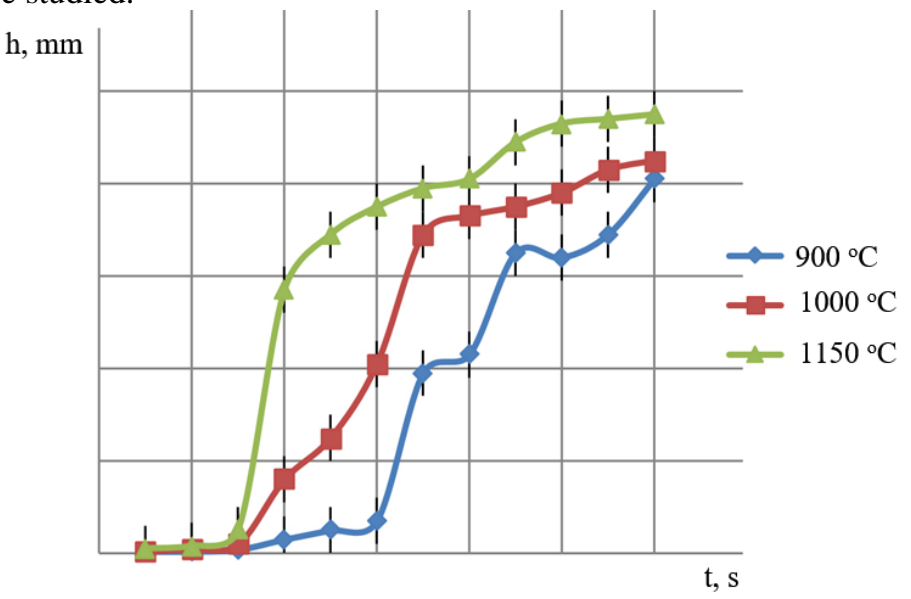

Fig. 1. Kinetic curves of $65 \mathrm{G}$ steel boriding from a mixture at temperatures of 900,1000 , and $1150{ }^{\circ} \mathrm{C}$. 
Anamorphoses of kinetic curves of 65G steel boriding using HFC-heating in linear coordinates of the Erofeev-Kolmogorov equation are shown in Figures 2-4.

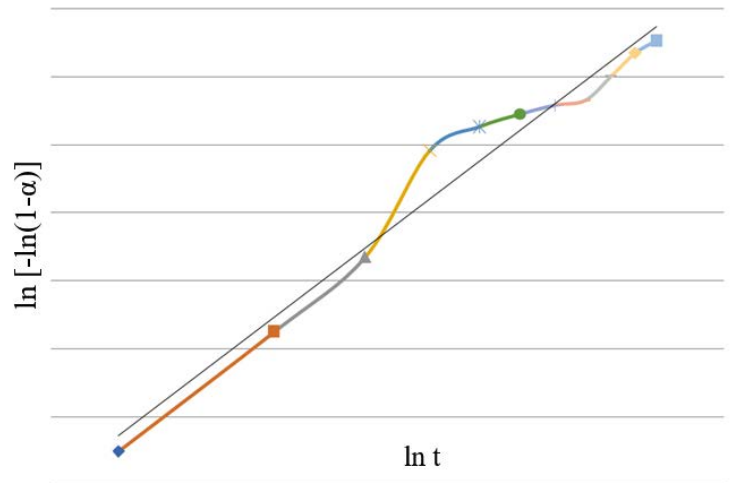

Fig. 2. Anamorphoses of kinetic curves of 65G steel boriding using HFC-heating in linear coordinates of the Erofeev-Kolmogorov equation at $1198 \mathrm{~K}$.

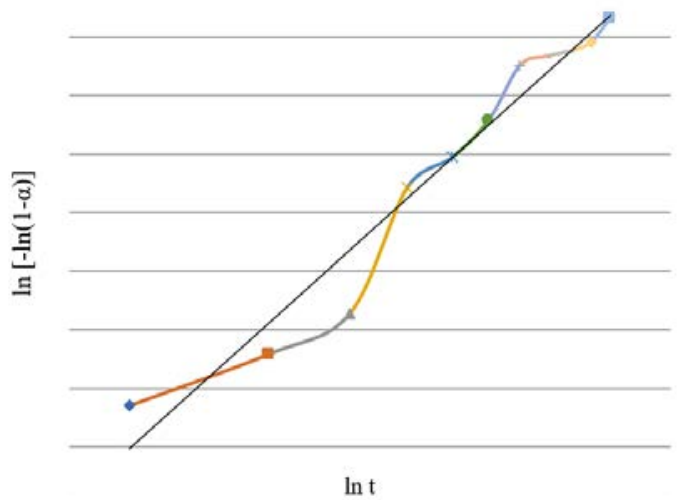

Fig. 3. Anamorphoses of kinetic curves of 65G steel boriding using HFC-heating in linear coordinates of the Erofeev-Kolmogorov equation at $1298 \mathrm{~K}$.

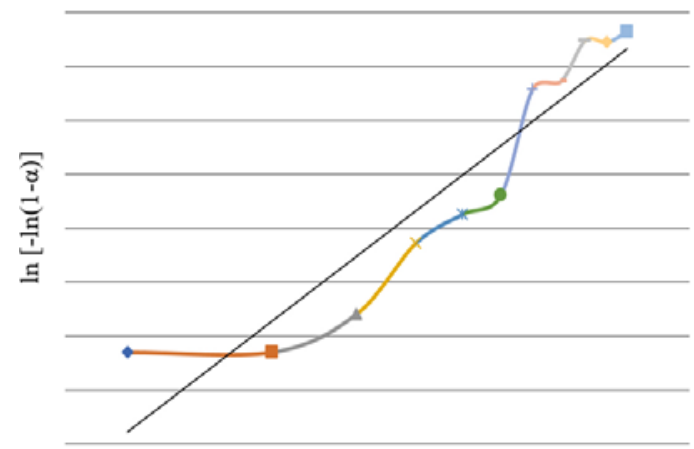

$\ln \mathrm{t}$

Fig. 4. Anamorphoses of kinetic curves of 65G steel boriding using HFC-heating in linear coordinates of the Erofeev-Kolmogorov equation at $1448 \mathrm{~K}$. 
To determine the TCR activation energy, let's use the equation proposed by S. Arrhenius:

$$
\frac{d \ln k}{d T}=\frac{E_{\alpha}}{R T^{2}},
$$

where $\mathrm{k}$ - reaction rate constant,

$E_{a}$ - activation energy,

$T$ - process absolute temperature,

$R$ - universal gas constant.

Arrhenius equation integration results in a dependence of reaction velocity (via the rate constant) on temperature:

$$
\ln k=-\frac{E_{\alpha}}{R T}+\text { const, }
$$

Most generally, it turns out that the activation energy of the majority of real processes (diffusion, chemical, or mixed) depends on temperature. As a rule, this is due to their proceeding through several stages, the rates of which vary in different ways at different temperatures.

However, assuming that the formation of a coating layer in the process of boriding using HFC-heating is due to one, albeit hypothetical, lumped multistage topochemical reaction of type (2), the kinetics of which have been already studied and the thermodynamic potentials estimated, then the activation energy can be considered constant in the temperature range of practical implementation of boriding using HFC heating from 1198 to $1448 \mathrm{~K}$.

When integrating the Arrhenius equation in a small $T_{1}-T_{2}$ temperature range, where it can be assumed that the chemical reaction $\mathrm{E}_{a}$ does not depend on temperature, the following expression is obtained:

$$
\int_{T_{1}}^{T_{2}} \frac{d \ln k}{d T}=\ln K T_{1}+\frac{E_{a}\left(T_{2}-T_{1}\right)}{R \cdot T_{1} \cdot T_{2}},
$$

from which it is easy to obtain an expression for the analytical determination of the activation energy, when a chemical reaction is carried out at two temperatures $T_{1}$ and $T_{2}$, its kinetics is studied, and the values of the chemical reaction rate constant at these temperatures $\mathrm{kT}_{1}$ and $\mathrm{kT}_{2}$ are found:

$$
E_{\alpha}=\frac{R \cdot T_{1} \cdot T_{2}}{T_{2}-T_{1}},
$$

We have calculated the values of the activation energy of 65G steel boriding from a mixture using HFC-heating according to formula (15) and on the basis of linearization of the Arrhenius equation (fig. 5).

The processing of linearized TCR kinetic curves by LSM made it possible to establish the parameters of the kinetic equation (9) for the process of steel boriding using HFC-heating ( $\mathrm{k}$, n) and calculate the apparent activation energy of TCR TPCHR (Ea*) according to the Arrhenius equation (Table 1). 


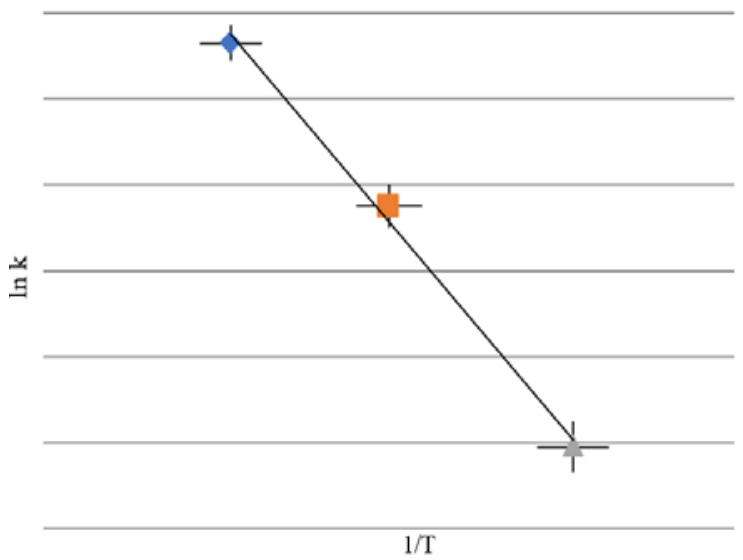

Fig. 5. Linearized Arrhenius equation.

Table 1. Kinetic parameters of high-speed HFC-boriding of 65G steel using HFC-heating ( $\mathrm{n}=5$; $\mathrm{P}=0.95)$

\begin{tabular}{|c|c|c|c|c|c|c|}
\hline \multirow{2}{*}{$T,[K]$} & \multirow{2}{*}{$\ln (\mathrm{k})$} & \multirow{2}{*}{$n$} & \multicolumn{3}{|c|}{$\sigma, m=$ const } & \multirow{2}{*}{$E_{a}{ }^{*},[\mathrm{~kJ} / \mathrm{mole}]$} \\
\cline { 4 - 6 } & & & 1 & 2 & 3 & \\
\hline 1198 & $-10.35 \pm 0.03$ & $2.72 \pm 0.02$ & 1.72 & 0.72 & - & \multirow{2}{*}{$365.8 \pm 0.2$} \\
\hline 1298 & $-12.25 \pm 0.02$ & $3.32 \pm 0.03$ & 2.32 & 1.32 & 0.32 & \\
\hline 1498 & $-15.05 \pm 0.03$ & $4.15 \pm 0.03$ & 3.15 & 2.15 & 1.15 & \\
\hline
\end{tabular}

\section{Conclusions}

Kinetic curves of $65 \mathrm{G}$ steel boriding using HFC-heating at various temperatures were obtained. Anamorphoses of kinetic curves of boriding are plotted, and the values of activation energy and kinetic parameters of the borating process using HFC-heating are obtained on the basis of linearization of the Arrhenius equation. Following the conducted thermodynamic and kinetic studies, it was possible to confirm the possibility of TCR boriding using boronizing mixture and applying HFC-heating.

\section{References}

1. Z. Hou, Y. Zhao, W. Zeng, Effect of Heat Treatment on the Microstructure Development of TC21 Alloy, Xiyou Jinshu Cailiao Yu Gongcheng/Rare Metal Mater. Eng. 46 (8) (2017) 2087-2091.

2. T. Zhu, M. Li, Effect of hydrogen addition on the microstructure of TC21 alloy, Mater. Sci. Eng. A. 527 (26) (2010) 7080-7085.

3. Y.S. Zhu, W.Z. Lu, D.W. Zuo, Microstructure and tribological properties of REs borided TC21 alloy, Surf. Eng. 30 (8) (2014) 612-618.

4. Y.S. Zhu, W.Z. Lu, D.W. Zuo, Y.L. Sun, H. Wang, J. Xu, Effects of rare earth additions during surface boriding on microstructure and properties of titanium alloy TC21, Mater. Sci. Tech. 30(14) (2013) 1765-1769.

5. L.C. Zhang, L.Y. Chen: Wang, Surface Modification of Titanium and Titanium Alloys: Technologies, Developments, and Future Interests, Advanced Engineering Materials. 22 (2019) DOI: 10.1002/adem.201901258. 
6. M. Kul, K.O. Oskay, A. Temizkan: Effect of boronizing composition on boride layer of boronized GGG-60 ductile cast iron, Vacuum. 126 (2019) 80-83.

7. A. Kaouka, K. Benarous, Electrochemical boriding of titanium alloy Ti-6Al-4V, J. Mater. Res. Tech. 8(6) (2019) 6407-6412.

8. P. Li, D. Liu, W. Bao, Surface characterization and diffusion model of pack borided TB2 titanium alloy, Ceram. Int. 44 (15) (2018) 18429-18437.

9. Y. Duan, P. Li, Z. Chen, Surface evolution and growth kinetics of Ti6Al4V alloy in pack boriding. J. Alloys Compoun. 742 (2018) 690-701.

10. H. Attar, M. Bönisch, M. Calin, Selective laser melting of in situ titanium-titanium boride composites: Processing, microstructure and mechanical properties, Acta Mater. 76 (2014) 13-22.

11. Y. Chen, J. Zhang, Corrosion Behaviour of Selective Laser Melted Ti-TiB Biocomposite in Simulated Body Fluid, Electroch. Acta. 232 (2017) 89-97.

12. Y. Duan, $X$. Wang, Characteristics, wear and corrosion properties of borided pure titanium by pack boriding near $\alpha \rightarrow \beta$ phase transition temperature, Ceram. Int. 46(10) (2020) 16380-16387.

13. Y.S. Zhu, W.Z. Lu, D.W. Zuo, A novel rare earth-salt bath nitriding of TC21-DT titanium alloy. Surf. Eng. 34(2) (2018) 128-131.

14. M.J. Peng, Y.H. Duan, Characteristics of surface layers on Ti6Al4V alloy borided with $\mathrm{CeO} 2$ near the transition temperature, J. Alloys Compoun. 769 (2018) 1-9.

15. Y.S. Zhu, W.Z. Lu, Effect of rare earth addition on diffusion kinetics of borided TC21DT titanium alloy, Surf. Eng. 32 (11) (2016) 795-801.

16. B. Sarma, N.M. Tikekar, Kinetics of growth of superhard boride layers during solid state diffusion of boron into titanium, Ceram. Int. 38 (8) (2012) 6795-6805.

17. M. Keddam, S. Taktak, Characterization and diffusion model for the titanium boride layers formed on the Ti6Al4V alloy by plasma paste boriding, Appl. Surf. Sci. 399 (2017) 229-236.

18. B. Sarma, K.S. Ravi Chandran, Accelerated kinetics of surface hardening by diffusion near phase transition temperature: Mechanism of growth of boride layers on titanium, Acta Mater. 59 (10) (2011) 4216-4228.

19. A.G. Merzhanov, I.P. Borovinskaya, Yu.E. Volodin, On the mechanism of combustion of porous metal samples in nitrogen, Repor. USSR Academ. Sci. 206(4) (1972) 905-908.

20. V.I. Itin, Yu.S. Nayborodenko, High-temperature synthesis of intermetallic compounds, Tomsk State University, Tomsk, 214, 1989.

21. A.V. Ishkov, V.N. Malikov, The study of the wear of the control knives of the straw chopper, J. Phys.: Conf Ser. 1515(5) (2020) 1-5.

22. S. Dmitriev, V. Malikov, A. Ishkov, Investigation of thermal fields at phase boundaries in powder mixtures that are subject to melting and chemical transformation, Mat. Sci. For. 992 (2020) 1011-1015 